\title{
MEMÓRIA, PATRIMÔNIO E DISSONÂNCIAS: FERRAMENTAS CONCEITUAIS E EPISTEMOLÓGICAS PARA UMA MUDANÇA DE PARADIGMAS
}

\author{
MEMORY, HERITAGE AND DISSONANCE: \\ CONCEPTUAL AND EPISTEMOLOGICAL TOOLS FOR A \\ CHANGE OF PARADIGMS
}

Giulia Crippa

\begin{abstract}
RESUMO
Objetivos: Analisar as interações entre o conceito de patrimônio como objeto de construção histórica e seus efeitos no contexto das práticas sociais atuais. Observar as relações entre Cultura, Identidade Nacional e Patrimonio. Discutir o conceito de Patrimônio Dissonante, através de um estudo de caso, o Monumento a Ferdinando I Grão-Duque de Toscana, conhecido como Os quatro Mouros. Metodologia: Trata-se de um estudo qualitativo de natureza teórica, portanto bibliográfico, que busca, de forma ensaística, lançar mão de questões epistemológicas. Resultados: A proposta de utilizar o conceito de patrimônio dissonante desempenha um papel de crítica da violência da modernidade, podendo incidir na elaboração de uma memória cultural que enfrente a hierarquização étnica, de classe e de gênero diferentes. Considerações finais: A elaboração e aplicação do conceito de patrimônio dissonante permite que o patrimônio desempenhe a função: de reorganizar as memórias de forma abrangente e não mais atrelados à ideia de culturas identidades nacionais unificadoras.
\end{abstract}

Descritores: Patrimônio Dissonante. Monumentos. Políticas Patrimoniais. Epistemologia. Democratização da Cultura.

\section{INTRODUÇÃO}

O patrimônio cultural constituído por monumentos e estátuas tem uma dupla função, na representação do passado. Por um lado, trata-se do legado comemorativo público de memórias que cada época quis perpetuar e comunicar ao futuro. Por outro lado, sobretudo para os estudiosos, trata-se do conjunto de

\footnotetext{
a Doutora em História Social pela Universidade de São Paulo (USP). Docente da Faculdade de Filosofia, Ciências e Letras de Ribeirão Preto. Docente do Departamento de Bens Culturais da Universidade de Bolonha (Itália). E-mail: giulia.crippa2@unibo.it
} 
documentos que atuam como fontes de estudo do passado e de seus valores (LE GOFF, 1978). Quando esses símbolos entram nas pautas de movimentos sociais, ou quando o próprio poder público resolve retirá-los de seu local ou deixá-los às injúrias do tempo, é porque a mensagem comemorativa que lhes foi confiada no passado é questionada ou perdeu o sentido para os grupos que os propuseram ou para outros grupos sócias. É importante determinar quais aspectos do passado são ignorados ou deturpados na interpretação do patrimônio. Locais inteiros podem estar ausentes da consciência pública e, portanto, dos registros patrimoniais, talvez porque o público em questão não queira se lembrar dos valores associados a esses locais. Mesmo que, hoje, as pautas inclusivas sejam parte de qualquer discurso patrimonial, existem monumentos, e memórias que ainda são - ou se tornaram - difíceis de administrar, merecendo, portanto, uma atenção especial.

Um dos pilares contemporâneos da sustentabilidade social e cultural do patrimônio é o envolvimento das diversas comunidades locais no processo de patrimonialização (VOLPE, 2016). Essa abordagem bottom-up é particularmente importante quando se trata dessa tipologia de patrimônio, que chamaremos dissonante. Entretanto, ela também é complexa, justamente pelas características contestadas desta tipologia de patrimônio.

Observa-se a presença dialética de duas opiniões claramente delineadas. De um lado, a tomada de ações políticas e sociais quem consideram legitima a própria remoção/destruição dessas memórias em função de suas narrativas racistas, colonialistas e/ou totalitaristas. É uma das estratégias de luta contra a opressão social do passado e do presente. Do outro lado, elide-se o debate limitando-se à condenação dessas ações, definidas como atos vandálicos contra o patrimônio. Nesse caso, a resposta se limita à criminalização dos autores e dos atos. Entre essas posições extremas há, obviamente, muitos matizes que interessam os profissionais do patrimônio.

A dificuldade/dissonância do patrimônio manifesta-se nas estratégias interpretativas criadas pelas várias comunidades envolvidas, que realizam sua avaliação. Essa avaliação, por sua vez, decorre da tipologia dos materiais (por exemplo, materiais altamente sensíveis) e dos objetos, das condições históricas 
e culturais, das contingências políticas, das questões éticas, religiosas e legais presentes, das crenças e das motivações dos grupos envolvidos no processo. Como consequência dessa dialética, cheia de tensões e de conflitos, os profissionais que se ocupam da sustentação e da gestão do patrimônio encontram novos desafios: os ataques contra as memórias que simbolizam racismos, colonialismos, totalitarismos e outras manifestações dessa natureza obrigam a considerar a necessidade de novas políticas patrimoniais e de memória, que discutam os princípios e os valores do culto preservacionista que se manifesta, perante os monumentos, através de um entendimento de patrimônio histórico e cultural fundado em concepções europeias iluministas.

Nesse estudo, de natureza qualitativa e bibliográfica, o objetivo é traçar uma topografia das interações entre o conceito de patrimônio como objeto de construção histórica e seus efeitos no contexto das práticas sociais atuais. Tratase de uma revisão teórico-epistemológica do tema tratado, em que que se observa como o conceito de Patrimônio, historicamente construído, se tornou socialmente dissonante e precisa ser enunciado em formas novas. Consideramos que explorar essa dissonância cultural permite refletir sobre algumas questões epistemológicas, auxiliando na reflexão e no enfrentamento dos desafios atuais no campo da Memória e do Patrimônio.

Na primeira parte do trabalho, observaremos como o conceito "tradicional" de patrimônio se constitui com a época das Luzes, parte do projeto de modernização civilizatória que, paradoxalmente, está na base da própria dissonância de muitos patrimônios hoje. Em seguida, observaremos um exemplo de patrimônio dissonante, o monumento ao Grão Duque Ferdinando I de Toscana, melhor conhecido como "Os Quatro Mouros", na cidade de Livorno. Encerra essa discussão epistemológica a tentativa de definir o Patrimônio Dissonante.

\section{DA CULTURA DAS LUZES À CULTURA NACIONAL}

Até meados do século $\mathrm{XX}$, a oferta artística e cultural legítima era reservada a uma única classe, e somente aquela classe se aproximava dela. Essa oferta tinha, como efeito, a definição das classes, a segregação de parte 
delas e de suas manifestações. Dessa forma, a tipologia do consumo cultural e estético revelava, assinalava e protegia a divisão das classes e, para o sistema funcionar, os objets d'art eram confiados a locais mutuamente exclusivos, onde, em princípio, o conteúdo e sua qualidade não era relevante: o que importava era sua incompatibilidade com outros conteúdos. Tal divisão ainda está bem presente no ideário do conceito de patrimônio no Ocidente, e constitui um dos aspectos da estratificação social, na medida em que essa estratificação social das práticas culturais alimenta os debates e orienta as escolhas das políticas culturais.

Bourdieau (1998) desenvolve um modelo teórico em que os elementos constitutivos dos estilos de vida individuais resultam do habitus, o conjunto de disposições e estruturas de percepção incorporadas ao longo dos diversos estágios de socialização (como os hábitos alimentares, as escolhas morais, as opiniões políticas, os gostos, as práticas culturais...). Por sua vez, o habitus de classe participa da elaboração e codificação das práticas simbólicas entre grupos sociais, reforçando sua coesão interna. Assegura-se, assim, a reprodução das classes sociais através da transmissão do Capital Cultural, que cria diversidades de tratamento difíceis de compensar, na medida em que não é imediatamente visível e gera fronteiras entre os grupos sociais.

Se o espaço do gosto e dos hábitos culturais é socialmente diferenciado e hierárquico, impregnado de questões de poder, então práticas e preferências culturais, unidas à posição social dos indivíduos, se unem, por relações de homologia inseridas na concepção unificada e hierárquica dos espaços e dos estilos de vida. As identidades sociais dos indivíduos espelham, assim, a adesão positiva às preferências de seu ambiente e a aversão para as de outros grupos, enquanto o espaço social do gosto e das práticas culturais organiza-se em função do volume e da natureza do capital econômico e cultural.

A familiaridade com a cultura erudita e a negação da cultura popular e de massa ainda estabelece uma oposição entre classe dominante e dominada.

É importante lembrar que o espaço social estruturado pela hierarquia de gostos e práticas constitui um espaço de dominação simbólica, baseado na interiorização da ordem da legitimidade cultural. Para Bourdieau (2007), a cultura 
é a ferramenta utilizada de forma consciente para marcar as diferenças de classe e perpetuar tais diferenças. Se a cultura, então, é uma tecnologia para a criação e a manutenção das classes e das hierarquias, torna-se necessário voltar o olhar para aquela cultura representada pela elite, a cultura hegemônica que elege atores capazes de fornecer significados a algo que define culturalmente próprio. Há algo aleatório, nisso, no sentido que tudo isso se baseia na legitimidade cultural, socialmente construída em sua autoridade: distinguir a cultura "própria" da "imprópria" responde a necessidades sociais, e as modalidades disso variam no tempo e no espaço.

A cultura adquire, na análise de Bourdieau (1998), o papel de força conservadora, através de dois movimentos: ela se torna enfática e intransigente em suas escolhas e cria rótulos para indicar o que é próprio e impróprio. Nesse sentido, Bourdieau (2007) mostra a inversão do conceito iluminista de cultura como agente de transformação, e não de preservação do status quo. Com as Luzes, a cultura se torna ferramenta de orientação para a evolução "universal" da humanidade. Mesmo reconhecendo os limites etnocêntricos e as implicações históricas dos conceitos de "evolução" e de "universal" (JULLIEN, 2018), há de se destacar uma ideia bastante diferente da cultura enquanto registro de descrição, inventario, codificação. A cultura passa a ser vista de forma projetiva, para fixar uma meta nos esforços futuros, uma missão de proselitismo com a finalidade de educar as massas e refinar seus costumes. As Luzes elaboraram um ideal de progresso social através da democratização da cultura de seus representantes, para libertar o "povo" da cultura impropria. No dicionário da Modernidade, então, a cultura é uma missão civilizatória (HOBSBAWM, 1979). Essa proposta, porém, se apoia no acordo unilateral de direção hegemônica - e aleatória - entre "cultos" e "incultos", com o objetivo declarado de educar, ilustrar, elevar os segundos, que através da cultura se tornam cidadãos do Estado-Nação burguês. $O$ ideal iluminista atribui à cultura o status de ferramenta essencial para construir uma Nação. Em um primeiro momento, o projeto aparenta se realizar: as massas parecem orientadas a se tornar cidadãos e aumenta a confiança nas estruturas do Estrado-Nação.

A consolidação das estruturas gera um crescimento econômico e um 
desenvolvimento técnico e tecnológico que provoca a necessidade de expansão para novos territórios, dando vida aos fenômenos de emigração e de colonização imperialista. É aqui que podemos localizar o limite do projeto das Luzes, quando se transforma em formula ideológica de "exportação" para apoiar - e justificar a colonização imperialista do século XIX: se antes procurava-se esclarecer as massas através da cultura, agora a missão é "resgatar" os povos primitivos de sua barbárie e ignorância. Decorre disso o desenvolvimento de um complexo aparelho teórico e científico de sustentação de uma cultura evolucionista eurocêntrica, cujo ponto de partida é elevar o mundo tecnologicamente desenvolvido a modelo de civilização (AIME, 2020). Quem não se encontrar nesse modelo deve ser auxiliado ou, em caso de recusa, obrigado a aderir a seus parâmetros. Bourdieau (1998; 2007) estuda as práticas culturais bem no momento em que essa ideologia encontra seu limite: no mundo colonial, onde alega ter sido expulsa antes do sucesso. Enquanto isso, na Europa, depois de dois séculos de atuação, fica consolidada uma rede de instituições culturais fundadas e gerenciadas principalmente pelo Estado-Nação ou por seus apoiadores. Nesse cenário, a cultura se torna um dispositivo de manutenção, proteção e estabilização do Estado Nação contra qualquer hipótese de mudança. De arsenal de modernização, a cultura se torna depósito de produtos a serem preservados, ao serviço do status quo, bem diferente da ideia de agente de transformação. O fundamento da Memória Cultural é, assim, um circuito de criação, preservação, percepção e lembrança, sem algo realmente atual.

À luz disso, observa-se que uma das vertentes dos atuais conflitos sobre a memória cultural de estátuas e monumentos é de natureza epistêmica: fundase, de fato, nas concepções "modernas" de Nação e, principalmente, de Identidade Nacional, declinada a partir da Cultura Nacional e de seu Patrimônio, enquanto memórias institucionalizadas pela própria Nação. De fato, mesmo em momentos de ampliação do acesso à riqueza nacional e de ampliação de direitos civis, as bases do passado nacional permaneceram, em geral, intactas. Observese, por exemplo, o movimento pelos Direitos Civis dos Estados Unidos, que buscou legitimar-se operando uma releitura radical da tradição religiosa e política da fundação da "América", sem negar os mitos fundadores da democracia 
americana. Na França, até hoje há uma unanimidade em destacar o legado da Revolução Francesa, rejeitada apenas pelas franjas da direita mais radical e pelos monarquistas. Os próprios movimentos anticoloniais da Ásia e da África incorporaram, dialeticamente, a linhagem progressista e revolucionária do Ocidente, mesclados a valores políticos e culturais locais, com o surgimento de movimentos de libertação nacional que incorporam o discurso nacionalista e a linguagem dos direitos, incluindo-se o direito fundante do próprio liberalismo, o direito à rebelião contra a tirania (FERRO, 1999)

Entretanto, a emergência de um pensamento pós-colonial no fim do século $X X$ foi além, exigindo não apenas o reconhecimento do direito político à independência nacional, mas a revisão dos fundamentos da própria história ocidental e de sua autoindulgência liberal, que se manteve intacta (MIGNOLO, 2003; QUIJANO, 2010; SPIVAK, 2010).

Para Stuart Hall (2011), em geral, relacionamos a Identidade Cultural com a Nação ou com identidades expandidas e, ainda assim, geopoliticamente marcadas: as identidades "europeia", "latino-americana", "africana", todas ligadas a "comunidades imaginadas" - e que, precisamente por isso, devem constituir uma identidade cultural para sua existência.

A Nação, comunidade imaginada, é simbólica, e a Cultura Nacional a representa. A formação de uma Cultura Nacional levou à criação e manutenção de instituições culturais como bibliotecas, museus, arquivos; além disso, desempenhou um papel-chave nos processos de industrialização, tornando-se um verdadeiro dispositivo da modernidade.

Sobre identidade, Stuart Hall sintetizou em uma entrevista de forma muito objetiva o que tem escrito nas últimas décadas:

Acho que a identidade cultural não é fixa, é sempre híbrida. Mas é justamente por resultar de formações históricas específicas, de histórias e repertórios culturais de enunciação muito específicos, que ela pode constituir um 'posicionamento ao qual nós podemos chamar provisoriamente de identidade. (HALL, 2011, p. 409).

Para Bhabha (2007), a Cultura Nacional é o discurso que as instituições culturais produzem sobre símbolos e representações aos quais se atribuem significado em histórias e memórias. 
A ideia de Nação se declina de várias formas, pelas diferenças nos materiais culturais e nas práticas sociais, na elaboração dos discursos de cada cultura nacional, desenvolvida através de diversas estratégias:

1) Narrativas da Nação (através da história nacional e da literatura na mídia e na cultura popular): histórias, imagens, cenários, eventos coletivos, símbolos e rituais que representam experiências compartilhadas, perdas, triunfos e desastres que dão sentido à própria Nação.

2) Ênfase nas origens, continuidade, tradição e atemporalidade: os elementos "essenciais" do "caráter nacional" permaneceriam inalterados, apesar da História.

3) Invenção de tradições: um conjunto de práticas de natureza ritual ou simbólica que procuram inculcar valores e normas de comportamento através da repetição, que implica na continuidade com o passado histórico adequado.

4) A construção de mitos de fundação, histórias que localizam a origem de uma nação, um povo e seu "personagem" nacional em um passado distante, não histórico, mas mítico.

5) A ideia do povo/folk original (que raramente exerce o poder).

A Cultura Nacional quer unificar uma Identidade Cultural, mas encontra obstáculos nas diferenças de classe, gênero e etnia. Além disso, para que haja uniformidade é necessário anular e subordinar as diferenças culturais, enquanto a maioria das nações é formada por culturas separadas que foram unificadas por um longo processo violento de supressão forçada das diferenças, e sempre são constituídas por diferentes classes sociais, grupos étnicos e de gênero. Em suma, as culturas nacionais são um dispositivo discursivo que reduz a diferença à unidade de identidade: elas são atravessadas por profundas divisões e só são unificadas através do exercício de diferentes formas de hegemonia cultural. Através do controle e do monopólio da memória cultural, a cultura nacional se representa e representa os outros de maneira a moldar uma identidade ideal, apontando para os comportamentos apropriados para a inclusão e exclusão dos indivíduos (RENAN, 1990).

As identidades nacionais continuam, entretanto, a se representar como unificadas, expressões da cultura de "um só povo", mesmo sem respaldos 
históricos que permitam dizer que uma nação é composta por um único povo, uma única cultura, ou uma única etnia. As nações modernas são todas, sem exceção, híbridos culturais, e a ideia da Nação como Identidade Cultural unificada, não mais aceita em muitos âmbitos de discussão das ciências sociais e políticas, ainda mantém apelo quando o assunto são estátuas, monumentos e outros patrimônios controvertidos, dissonantes. As identidades nacionais não podem subordinar todas as diferenças e estão sujeitas a jogos de poder, divisões e contradições internas. Nesse sentido, todo patrimônio, de certa forma, é uma dissonância "unificada".

\section{3 “OS QUATRO MOUROS”: APAGAMENTO DA HISTÓRIA E DISSONÂNCIA DO MONUMENTO}

No centro de uma praça, perto do porto, em Livorno, há um monumento chamado Os Quatro Mouros, um patrimônio cuja dissonância não é reconhecida institucionalmente.

Figura 1 - Monumento Os Quatro mouros (1621)

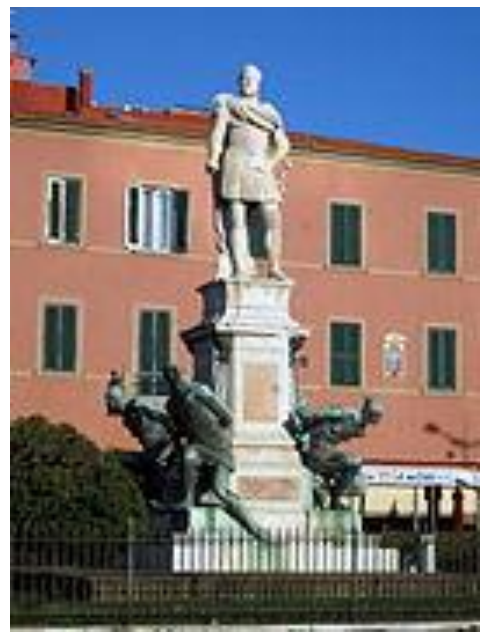

Fonte:

https://commons. wikimedia.org/w/index.php?search=quattro+Mori+livorno\&title=Special:MediaS earch\&go=Go\&type=image

Na primeira versão do monumento os quatro escravos acorrentados não estavam presentes, resultando composto apenas pela estátua de Ferdinando I, Grão Duque de Toscana. A estátua, de mármore branco, foi encomendada em 1595 a Giovanni Baldini, e seu objetivo era, naturalmente, de glorificar o Grão- 
Ducado. Ferdinando trouxe riqueza à cidade de Livorno, tornando-a um dos portos mais importantes do Mediterrâneo e uma das praças mais famosas contra os piratas. Como Grão-Mestre da Ordem de São Estêvão, não só rechaçou os ataques piratas, mas forneceu ao cristianismo uma pirataria igualmente capaz e cruel (ANGIOLINI, 2001). Os estefanianos (e não somente eles) não ficaram atrás de ninguém em pilhagem, estupro e escravidão.

A estátua permaneceu na periferia da cidade até que, em 1621, foi encomendada uma adição ao escultor Pietro Tacca: quatro escravos "mouros", acorrentados, foram colocados aos pés de Ferdinando. Era vital, para o grãoducado, deixar claro a seus cidadãos e visitantes o poder de Ferdinando e da cidade. Com essa imagem de homens subjugados e humilhados, o escultor retoma um tema da Antiguidade, o dos captivi, os prisioneiros de guerra, atualizando-o para a realidade do seu tempo: Livorno afirma ao mundo que sua riqueza se devia ao tráfico de escravos e à exploração do mar, e o monumento comemora a vitória sobre os otomanos obtida por Fernando na batalha de Lépanto. No entanto, hoje, é necessário perguntar: que visão de mundo expressa uma representação onde está presente a figura de um jovem com as características somáticas das populações subsaarianas? Esta visão, traduzida em monumento, que contribuição deu e ainda dá, do ponto de vista da construção do imaginário sobre a "alteridade"? Quando um turista, ou um transeunte, um membro das diversas comunidades presentes na cidade se depara com esse conjunto monumental, de que maneira se apropria de sua mensagem histórica e cultural? Os quatro homens acorrentados são de rara beleza. Apenas dois tem nome documentado: um velho com uma cicatriz no rosto, com adereços otomanos, Ali Salebbe (pela sua origem da cidade de Salé), e um jovem africano, de nome Morgiano, residente no balneário da cidade, uma fortaleza onde os escravos haviam sido aprisionados por séculos e onde 0 escultor o conheceu e estudou.

Olhando para as quatro figuras acorrentadas, aos pés de Ferdinando, especialmente para Morgiano, nota-se o quanto seu rosto se assemelha aos muitos imigrantes que hoje trabalham no campo, explorados e mal remunerados, na Apúlia, na Sicília, no Piemonte, originários da Etiópia, do Senegal ou da 
Nigéria. Homens que trabalham entre doze e catorze horas por dia por quantias irrisórias de dinheiro. Morgiano, um homem do século XVII acorrentado, se encontra monumentalizado, patrimonializado, na frente dos muitos que, por alguns centavos, apanham maçãs, tomates, cenouras e rabanetes destinados ao nosso mercado de frutas e vegetais que quer produzir o ano inteiro mas não está disposto a pagar o trabalho necessário para conseguir o que quer. Um novo tipo de escravidão que muitas vezes passa a ser considerado um mal necessário. A escravidão na Itália é uma realidade silenciosa em 2021, assim como muda é a história sobre essa prática comum na época em que o monumento foi realizado. Ninguém nunca pensa na Itália como lugar de escravidão.

Figura 2 -Detalhe do monumento Os quatro mouros: o Morgiano

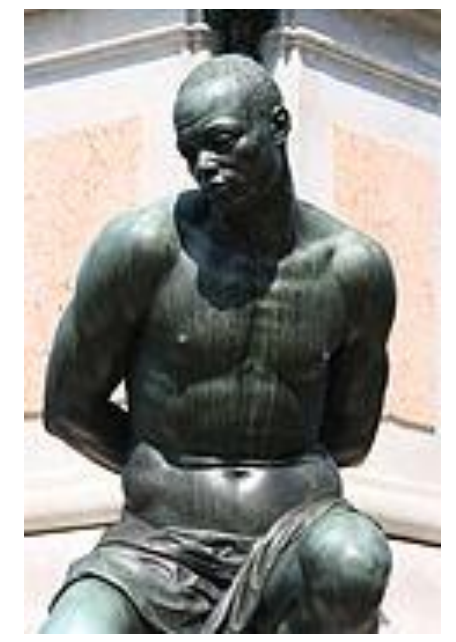

Fonte:

https://commons. wikimedia.org/w/index.php?search=quattro+Mori+livorno\&title=Special:MediaS earch\&go=Go\&type $=$ image

A Itália é reticente sobre o assunto, e o silêncio sobre o tráfico escravo desde o início da Idade Média até meados do século XIX parece ser não apenas uma forma de remover o passado, mas também de ocultar o presente. Os locais da escravidão do terceiro milênio, na Itália, muitas vezes são os mesmos da escravidão dos séculos XVI, XVII e XVIII: quando pensamos em escravidão, as imagens que nos vêm imediatamente à mente são as das Américas. Quase ninguém pensa em Trapani, Messina, Nápoles, Veneza, Livorno ou Roma como lugares de escravidão, ainda que muitos vestígios desse comércio permanecem na toponomástica e na arte italiana. Por uma questão de clareza, vale lembrar 
que a escravidão era recíproca em relação aos otomanos, mas não em relação às populações africanas: muitos europeus acabaram sob o domínio dos otomanos e cidades como Túnis, Trípoli, Argel e Salé estavam repletas de espanhóis, italianos, franceses, ingleses e até mesmo islandeses, escravizados.

Há muitos relatos desta escravidão branca, alguns ilustres, como o de Miguel de Cervantes, escravo em Argel durante cinco anos. O autor de Dom Quixote relatou sua experiência na peça El trato de Argel e repetiu o tema várias vezes em outras peças como La gran sultana, El gallardo español e Los baños de Argel. Mas se há reminiscências desta história em textos e mesmo em melodramas (além de Cervantes, se pense em L'italiana in Algeri de Gioacchino Rossini), o que aconteceu com os "outros" (isto é, africanos, árabes, turcos) só sabemos de fontes e material de arquivos e museus. Há muitos quadros que retratam a escravidão na Itália, por exemplo. A escrava vestida de laranja de Lorenzo Lotto que cuida de uma criança na obra Santa Lúcia na frente do juiz (1532), na Pinacoteca de Jesi;

\section{Figura 3 - Santa Lúcia na frente do juiz (1532)}

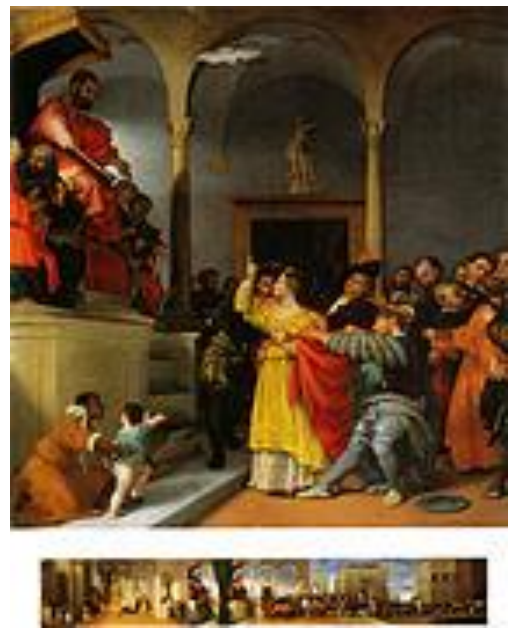

Fonte:

https://commons.wikimedia.org/w/index.php?search=Santa+Lúcia+davanti+al+giudice+Lotto\&titl e=Special:MediaSearch\&go=Go\&type=image

a escrava de Marco Marziale, ao lado de Jesus na Ceia de Emaus (c. 1506); 
Figura 4 - A ceia de Emaus (1506)

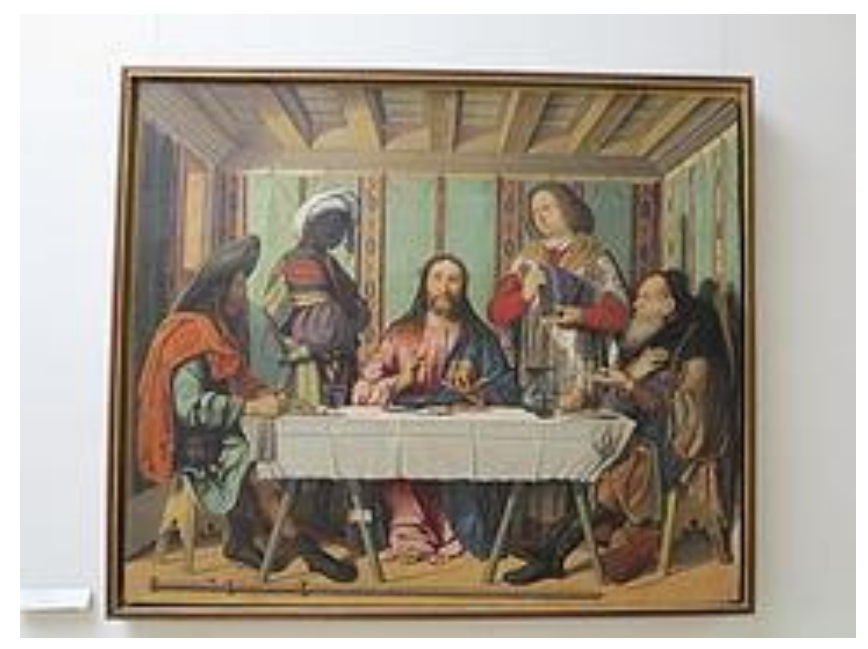

Fonte:

https://commons. wikimedia.org/w/index.php?search=Cena+di+Emmaus+marziale\&title=Special: MediaSearch\&go=Go\&type=image

os mouros acorrentados que pontilham as decorações do palacete veneziano Ca' Rezzonico, do século XVIII; os gondoleiros africanos, da Veneza do século XV de Carpaccio;

Figura 5 - Porta velas, Cá Rezzonico (séc. XVIII)

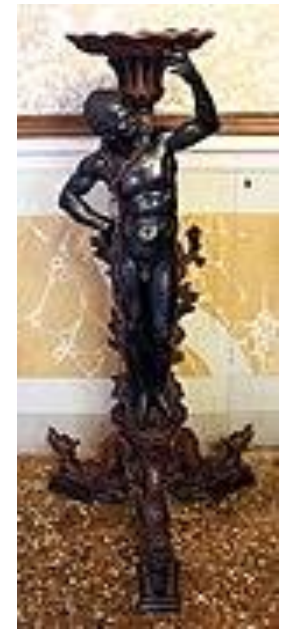

Fonte:

https://commons. wikimedia.org/w/index.php?search=Ca\%27+Rezzonico\&title=Special:MediaSe arch\&go=Go\&type=image

o adolescente num retrato do final do século XVIII, de Alessandro Longhi, entre outros tantos outros. 
Figura 6 - Detalhe da pintura "Milagre da relíquia da Cruz em Rialto" (séc. XV)

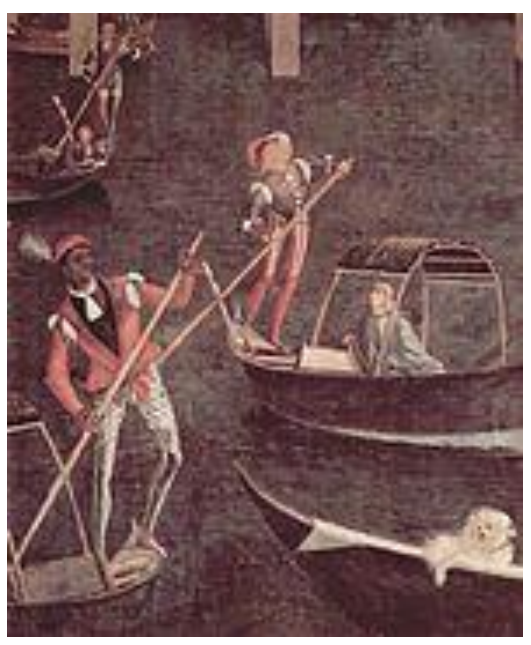

Fonte:

https://commons. wikimedia.org/w/index.php?search=gondoliers+carpaccio\&title=Special:Media Search\&go=Go\&type=image

Figura 7 - Moretto (séc. XVIII)

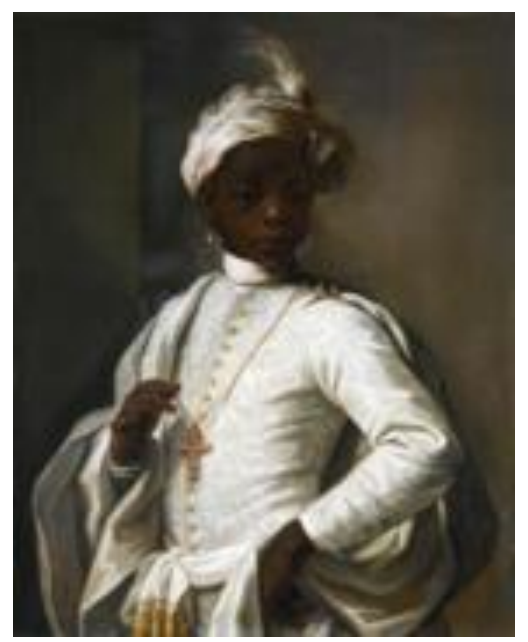

Fonte:

https://commons. wikimedia.org/w/index.php?search=Alessandro+Longhi+portrait\&title=Special: MediaSearch\&go=Go\&type=image

Na basílica de Santa Maria gloriosa dei Frari, em Veneza, encontra-se o monumento ao Doge Giovanni Pesaro, que apoia nos ombros de quatro negros com as feições distorcidas pela fadiga e com os olhos cheios de ódio: aqueles sobre os quais se apoia toda a riqueza são os escravos, e assim aparecem na arte italiana da época. Não encontramos estudos que aprofundassem o tema da representação do negro e do escravo na cultura e na arte italiana, abrindo-se um espaço de pesquisa sobre as possibilidades de tratamento dissonante do 
patrimônio.

Figura 8 - Detalhe doMonumento ao Doge Giovanni Pesaro (1669)

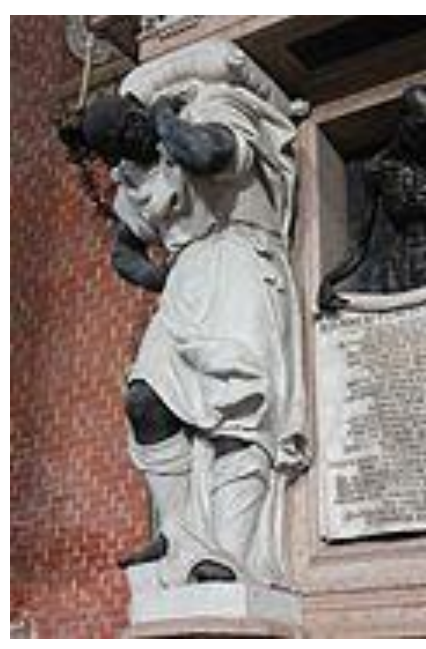

Fonte:

https://commons.wikimedia.org/w/index.php?search=monument++Doge+Giovanni+Pesaro\&title $=$ Special:MediaSearch\&go=Go\&type=image

A escravidão foi abolida, na Europa inteira, somente no século XIX. Na França, o decreto de abolição que vale para a metrópole e as colônias é assinado somente em 1848. Os estados italianos foram dos últimos a aboli-la, alguns somente depois da unificação do pais, em 1860.

Segundo Bono (2016), a escravidão mediterrânea afetou sete milhões de pessoas: africanos (principalmente da África Ocidental), árabes, turcos, espanhóis, franceses, judeus, ucranianos, magiares, gregos, alemães e escandinavos. A Itália desempenhou um papel importante nessa história, com um grande mercado que, em Nápoles, em 1661, contava mais de vinte mil escravos. Ter um escravo estava ao alcance de quase todos os bolsos. A Sicília também tinha os grandes mercados escravos de Messina e Trapani. De meados do século $X V$ até a primeira metade do século $X V I$, a ilha era centro do comércio da cana de açúcar, - as Américas entrariam na competição mais tarde. Para isso, precisava de mão-de-obra escrava.

Os historiadores destacam a importância das cidades costeiras para esse comércio, entre as quais Livorno, onde os mercados escravos eram alimentado pelos saques nas costas do Magrebe, pelas guerras contra o Império Otomano e pelos assaltos aos navios corsários concorrentes. Idosos e crianças custavam pouco, mas os adolescentes eram caros, e o mercado exigia homens saudáveis, 
inteiros, fortes o suficiente para suportar um trabalho duro no campo ou para não sucumbir remando em uma galé. Os escravos eram objetos de troca, podiam ser recebidos como prêmios e herdados, morriam de mortes violentas. As mulheres eram quase sempre estupradas por seus donos e, mesmo com a sorte de não serem abusadas sexualmente, tiveram que suportar vidas duras e trabalhos exaustivos.

Na Itália, como em outros países europeus, era muito difícil emancipar-se da escravidão e é interessante notar que há uma pequena presença de santos negros, especialmente na Sicília, que vieram da escravidão. Os mais conhecidos eram Antônio de Noto e Bento de São Fratello, ambos negros: o primeiro capturado por piratas sicilianos e escravizado, o segundo nascido de pais etíopes escravizados. (FIUME, 2009).

A escravidão mediterrânea durou até o início do século XIX. Depois, tudo foi colocado na gaveta, esquecido, retirado. Mas agora, no século XXI, a história está se repetindo nos mesmos lugares. O que está acontecendo hoje com os muitos senegaleses, magrebinos e indianos empregados na indústria agroalimentar faz parte do mesmo desenho de opressão, que liga o antigo ao moderno.

Mesmo Fernando I tendo sido uma importante figura histórica, o monumento a ele dedicado não pode e não deve ocupar o espaço público simplesmente como objeto de considerações estético-artísticas, alheias à dissonância. O Grão-Duque é uma peça no quebra-cabeça da política colonial da Europa Moderna, ele mesmo ambicionando o estabelecimento de suas próprias colônias (tanto no Brasil como na África). Ou seja: o monumento faz parte de uma história colonialista, ligada ao desenvolvimento de uma economia escravocrata.

\section{A DISSONÂNCIA COMO EPISTEMOLOGIA PARA O PATRIMÔNIO}

Até a Segunda Guerra Mundial, os critérios da memória pública passavam pelos heróis, os estadistas e os militares, e não pelas vítimas anônimas e coletivas. As memórias das vítimas, atravessadas por traumas e silêncios, eram transmitidas no âmbito privado ou encenadas em rituais simbólicos em espaços não legitimados pelo poder. É esse o conceito de "discurso autorizado" do patrimônio proposto por Smith (2006), que permite entender a natureza da 
dissonância. Em qualquer sociedade, os grupos hegemônicos utilizam sua visão do passado ao identificar os monumentos que compõem o patrimônio, atribuindo a especialistas de campos diversos a responsabilidade pela sua preservação.

Esse patrimônio autorizado é a expressão do poder hegemônico. Portanto, o patrimônio é dissonante por definição, porque vem de um processo social que visa tanto a legitimação quanto o exercício da memória, contestando e desafiando uma série de identidades culturais e sociais. Essa discussão, como podemos ver, remete às questões levantadas acima sobre o processo de unificação da Identidade no âmbito da Cultura Nacional. De fato, Smith (2006) e outros estudiosos, refletindo à luz dos Estudos Culturais sobre o campo do patrimônio, reconhece a criação de um discurso de patrimônio autorizado a partir da narrativa que promoveu o nacionalismo e a modernidade liberal, que inventou o conceito de universalismo ocidental e estimulou uma onda de leis de preservação. Entretanto, a preocupação com itens patrimoniais ou materiais do passado faz parte da condição humana (ARENDT, 1991). Ainda que as mudanças de rumo da memória social e da crítica historiográfica tenham pautados outras representações do passado no espaço público, elas ainda se atrelam às matrizes discursivas e simbólicas moldadas pelo nacionalismo ocidental, pelo culto da civilização e pelo patriotismo.

A lógica da relevância do Patrimônio opera dentro de um sistema vertical, hierárquico, de relação de poder, executando a tarefa de sustentar esta verticalidade, classificando (TURNER, 2020). Algo é relevante para um sistema se o auxilia a cumprir uma tarefa. A relevância atribuída ao patrimônio auxilia um determinado sistema a atingir um determinado objetivo. Como profissionais da Informação, temos que criar nossas próprias técnicas, regras, ética e práxis, pois lidar com os estilhaços do colonialismo, do totalitarismo e de outros traumas significa lidar com toda a violência que os atravessa, abraçar os conflitos relacionados com uma permanente decolonização do pensamento (ERNST, 2016). Refletir sobre patrimônios baseado na memória traumática se torna exercício de cultura cívica e democrática, independentemente da nacionalidade ou da disponibilidade de meios financeiros para preservar, usar e desfrutar desses patrimônios, discutindo o novo papel das próprias instituições na 
apropriação da dissonância dessas memórias (LEOPOLD, 2007).

$\mathrm{Na}$ Europa, o Estado tem sido tradicionalmente o garante da continuidade material e econômica do patrimônio, tanto que esta permanência é uma de suas características definidoras (VERDE, 2017; VOLPE, 2016; SOARES; CUREAU, 2015). O Estado, porém, incentiva ou abandona e bloqueia o desenvolvimento de políticas patrimoniais por diferentes razões. Num cenário de políticas neoliberais globais, por exemplo, o patrimônio tornou-se objeto de desejo para o mercado basicamente através da indústria do turismo, levando à políticas voltada principalmente para a valorização mais rentável. Nesse sentido, estamos assistindo a um significativo processo de "privatização" de memórias que modifica até mesmo agendas científicas e sociais.

O conceito de patrimônio dissonante se organiza em volta da crítica da violência da modernidade, face os processos de construção da memória cultural, da hierarquização de etnias, classes e gêneros diferentes e da criação de circuitos fechados de reprodução socioeconômica e cultural. Tais processos, por muito tempo, ignoraram a origem violenta desses dos patrimônios na esfera do imperialismo moderno - historicamente falando - bem como na política e micropolítica da (pós)modernidade praticada nas sociedades nacionais de hoje (VERDE, 2016). Não pode haver patrimônios socialmente compartilhados, hoje, sem que se reconheça sua dissonância, atrelando a isso a possibilidade de organizar a memória coletiva de sujeitos subalternos, etnicamente invisíveis ou racializados que vivem na Europa e fora dela, em países que muitas vezes os privam do direito de cidadania e dos direitos civis e políticos básicos (SOARES; CUREAU, 2015). O patrimônio dissonante é baseado na noção de memória como motor de ativação política no presente. Mesmo que a pluralidade e a consciência sejam, atualmente, parte de qualquer discurso patrimonial, existem monumentos, bens intangíveis, memórias que ainda são difíceis de administrar e merecem uma atenção especial. Esse aumento progressivo de memórias ainda a serem autorizadas marcam o caminho para uma mudança no discurso do patrimônio autorizado: não se trata mais de unificar todas as diferenças, sufocando aquelas que não se uniformam, mas de tornar presentes e polifônicas as dissonâncias envolvidas, caminho do qual ainda temos somente um vislumbre 
nas práticas cada vez mais bottom-up das comunidades e dos stakeholders envolvidos (GRAHAM; ASHWORTH; TUNBRIDGE, 2004).

As lutas antirracistas e anticoloniais que formaram o pensamento póscolonial aguçaram esse olhar crítico, questionando o núcleo constitutivo do "pacto cultural" da época das luzes antes exposto, que estruturou a autoimagem das sociedades ocidentais hegemônicas ao longo dos últimos séculos (CARVALHO, 2016).

Esse "pacto", como vimos anteriormente, foi chancelado pelas elites burguesas que se afirmaram no século XIX, tendo suas bases nas conquistas revolucionárias, moderadas ou radicais, que consagraram o lluminismo, 0 progresso técnico, o humanismo abstrato e o liberalismo como lentes para comemorar um passado comum. Nesse processo os fatos e heróis nacionais, mesmo aqueles ligados aos "antigos regimes" derrubados pela burguesia liberal, foram consagrados.

\section{CONSIDERAÇÕES FINAIS}

Chegamos, assim, aos impasses atuais que desafiam a afirmação de uma política patrimonial, e que desaguam na guerra aos monumentos e de narrativas mutuamente excludentes sobre o passado, com olhos nos conflitos do presente. O que fazer diante desse quadro? Como profissionais da informação e da memória, engajados em políticas que aprofundem a inclusão e a democratização da sociedade, é preciso defender políticas de memória respaldadas por uma historiografia crítica, capaz de destacar as dissonâncias. Uma memória pública crítica, capaz de reposicionar seu patrimônio de uma história nacional comemorativa, compartilhando com a historiografia o princípio de que 0 silenciamento das memórias dos traumas do processo histórico são insustentáveis sob o ponto de vista político, ético e epistemológico é uma memória aberta à dissonância. Essas premissas não significam que devemos analisar a história com a moral do presente, simplificando o conhecimento histórico como a eterna luta das classes populares oprimidas contra as elites malvadas. A análise crítica do passado deve ir além do mero julgamento moral, embora inevitavelmente passe por este, sob pena de derrapar no pior erro do 
historiador, o anacronismo.

Quanto mais o poder público e as instituições responsáveis não se posicionarem, ou tergiversarem, sobre a dissonância no patrimônio, maior é o risco de ações violentas contra ele. Durante os processos revolucionários moderno, o debate sobre o patrimônio sempre foi acirrado e dividiu as próprias lideranças, gerando novas concepções e usos do patrimônio herdado de regimes e épocas anteriores e ultrapassando a dialética das posturas ideológicas. $\mathrm{O}$ princípio da destruição do passado, nas revoluções, nem sempre prevaleceu, sejam na Revolução Francesa, ou na Revolução Russa. Em ambos os casos, as mudanças levaram a uma interpretação renovada dos monumentos existentes.

Por outro lado, a remoção dos monumentos e sua realocação em instituições de memória preocupa os profissionais mais atentos ao princípio de que museus não são mais depósitos de peças, não são lugares deputados à encenação de narrativas através da exposição serial de objetos mais ou menos antigos e sem uso cotidiano. Os museus procuram cada vez mais se tornar espaços de problematização do passado. Colocar os objetos do patrimônio dissonantes em museus não resolve o problema, limita-se a desloca-lo, na medida em que o museu é um dos lugares deputados às memórias socialmente compartilhadas. Essa escolha, então, não nos libera da tarefa de dar destaque às dissonâncias.

Para uma nova política de memória torna-se fundamental eleger alguns valores decorrentes dos direitos humanos com foco na democratização, na pluralidade cultural, no antirracismo e na inclusão social e, nesse sentido, o conceito de patrimônio dissonante é uma ferramenta que permite que monumentos e estátuas desempenhem uma nova função: a de serem os pivôs de discursos múltiplos e não mais unívocos, através da criação, por exemplo, além dos princípios abstratos, de comitês de gestão da memória pública com ampla participação da sociedade civil e de movimentos sociais, em diálogo com o debate historiográfico, o pensamento museológico, além do viés patrimonial e conservacionista estrito e de roteiros compartilhados entre as diversas comunidades abrangidas pelas dissonâncias. A identificação da dissonância do patrimônio e o tratamento possível responde a algumas questões: 
1. Queremos continuar a celebrar a pessoa ou evento que é o tema do patrimônio em questão? Ele responde aos valores que celebramos hoje? Se a resposta for ambígua, será necessário refletir mais sobre os valores que as diversas comunidades associam àquele patrimônio e seu significado.

2. Manter o patrimônio no lugar pode ter efeitos positivos imediatos para aqueles que a veem? Por exemplo, pode inspirar aqueles que o vem a ser uma pessoa melhor, um cidadão melhor?

3. Pode ter efeitos negativos diretos sobre o visitante? Por exemplo, as estátuas dos generais confederados que foram criadas especificamente para criar um ambiente urbano hostil ao povo negro, podem provocar sofrimento, considerando que se trata de símbolos da supremacia branca ou do racismo celebrado publicamente? Se tiver efeitos negativos, essas questões ainda são relevantes, como é o caso do supremacismo branco, ou são questões que a história (talvez) resolveu, como os crimes de guerra dos romanos?

Podemos avaliar esses pontos a partir de uma perspectiva comunitária, perguntando se existe um amplo consenso sobre o aspecto positivo ou se existe uma resistência generalizada ou pessoas ou grupos de pessoas que são afetados negativamente em demasia. Esta fase requer muita discrição, uma discussão comum na qual todos se ouvem e na qual todos podem falar, sabendo que muitos ficarão descontentes com o resultado final, mas que todos devem sentir que suas preocupações são levadas em conta. Se a avaliação final for positiva, o patrimônio poderá ser mantido no lugar. Se for negativa, talvez seja melhor que não fique onde está e seja transferido para um lugar onde possa continuar a ser preservado e estudado, mas privado do aspecto comemorativo associado à exposição pública: pode integrar uma coleção museológica somente a partir do momento em que seus valores dissonantes sejam declarados, estudados, destacados.

Seria impossível uma memória coletiva decorrente da remoção de todos os símbolos que remetem ao passado colonial, às ditaduras ou às violências de classe, "Já que o inteiro patrimônio cultural [...] nunca é documento de cultura 
aem ser, ao mesmo tempo, documento de barbárie" (BENJAMIN, 1962, p. 79). A de Benjamin parece que ainda não foi plenamente assimilada pelas políticas patrimonias. Só compreendendo o lugar e a natureza das violências do passado é que podemos evitar que elas se perpetuem no presente e não sejam sublimadas por estátuas e monumento.

A estátua do Morgiano de Livorno, hoje, olha para nós e pede, de volta, um olhar de dissonância ainda não reconhecido: ele é jovem, bonito e acorrentado para sempre, enquanto sua história permanece em silêncio.

\section{REFERÊNCIAS}

AIME, M. Classificare, separare, escludere: razzismi e identità. Torino: Einaudi, 2020.

ANGIOLINI, F. "I principi e le armi: i Medici granduchi di Toscana e gran maestri dell'ordine di Santo Stefano". In: FANTONI, M. II "perfetto" capitano: immagini e realtà (secoli XV-XVII). Roma: Bulzoni, 2001, p. 183-218.

ARENDT, H. Tra passato e futuro. Milano: Garzanti, 1991.

BENJAMIN, W. Angelus Novus: saggi e frammenti. Torino: Einaudi, 1962.

BHABHA, H. K. O local da cultura. Belo Horizonte: UFMG, 2007.

BONO, S. Schiavi: una storia mediterranea (XVI-XIX secolo). Bologna: il Mulino, 2016

BOURDIEAU, P. A distinção: crítica social e julgamento. São Paulo: Edusp, 2007.

BOURDIEAU, P. O poder simbólico. Rio de Janeiro: Bertrand Brasil, 1998.

CARVALHO, A. Museus e diversidade cultural: da representação aos públicos. Lisboa: Patrimônio cultural, 2016.

ERNST, W. "Radically De-Historicizing the Archive: Decolonising Archival Memory from the Supremacy of Historical Discourse". In: AA.VV. Decolonising Archives. Ghent: L'Internationale Books, 2016.

FERRO, M. História das colonizações: de conquistas às independências (séculos XIII a XX). São Paulo: Companhia das Letras, 1999.

FIUME, G. Schiavitù mediterranee: corsari, rinnegati e santi di età moderna. Milano: Bruno Mondadori, 2009 
GRAHAM B. J.; ASHWORTH, G.; TUNBRIDGE, J. A geography of heritage: power, culture and economy. London, Arnold, 2004.

HALL, S. Da diáspora: identidades e mediações culturais. Belo Horizonte: UFMG, 2011.

HOBSBAWM, E. (org.). A invenção das tradições. Rio de Janeiro: Paz \& Terra, 1997.

HOBSBAWM, E. Il trionfo della borghesia (1848-1875). Bari: Laterza, 1979.

JULLIEN, F. L'identità culturale non esiste. Torino: Einaudi, 2018.

LE GOFF, J. "Documento/Monumento". In: AA.VV.: Enciclopédia Einaudi, v. 5. Torino: Einaudi, 1978, p. 38-48.

LEOPOLD, T. "A proposed code of conduct for war heritage sites". In: RYAN, C. (ed.). Battlefield Tourism: History, Place and Interpretation. Elsevier, 2007.

MIGNOLO, W. Histórias locais/Projetos globais: colonialidade, saberes subalternos e pensamento limiar. Belo Horizonte: UFMG, 2003.

QUIJANO, A. Colonialidade do poder e classificação social. In: SANTOS, B. de S; MENESES, M. P. (org.). Epistemologias do Sul. São Paulo: Cortez, 2010. p. 73-118.

RENAN, E. What is a nation? In: Bhabha, Nation and narration. London: Routledge, 1990, p. 8-22.

SMITH, L. Uses of Heritage. London: Routledge, 2006.

SOARES, I. V. P.; CUREAU, S. Bens culturais e direitos humanos. São Paulo: SESC, 2015.

SPIVAK, G. Pode o subalterno falar? Belo Horizonte: UFMG, 2010.

TURNER, $\mathrm{H}$. Cataloguing culture: legacies of colonialism in museum documentation. Toronto: UBCPress, 2020.

VERDE, S. Le belle arti e i selvaggi: la scoperta dell'altro, la storia dell'arte e l'invenzione del patrimonio culturale. Venezia: Marsilio, 2017.

VOLPE, G. Un patrimonio italiano: beni culturali, paesaggio e cittadini. Novara: UTET, 2016.

\section{MEMORY, HERITAGE AND DISSONANCE: CONCEPTUAL AND EPISTEMOLOGICAL TOOLS FOR A CHANGE OF PARADIGMS}




\begin{abstract}
Objectives: To analyze the interactions between the concept of heritage as an object of historical construction and its effects in the context of current social practices. To observe the relationship between Culture, National Identity and Heritage. To discuss the concept of Dissonant Heritage through a case study, the Monument to Ferdinand I Grand Duke of Tuscany, known as The Four Moors. Methodology: This is a qualitative study of a theoretical nature, therefore bibliographical, which seeks, in an essayistic way, to launch hand of epistemological questions. Results: The proposal to use the concept of dissonant heritage plays a role of critique of the violence of modernity, and may focus on the elaboration of a cultural memory that confronts the different ethnic, class and gender hierarchization. Final considerations: The elaboration and application of the concept of dissonant heritage allows heritage to perform the function: of reorganizing memories in a comprehensive way and no longer tied to the idea of unifying national identities cultures.
\end{abstract}

Descriptors: Dissonant Heritage; Monuments; Heritage Policies; Epistemology; Democratization of Culture.

\title{
MEMORIA, PATRIMONIO Y DISONANCIA: HERRAMIENTAS CONCEPTUALES Y EPISTEMOLÓGICAS PARA UN CAMBIO DE PARADIGMAS
}

\section{RESUMEN}

Objetivos: Analizar las interacciones entre el concepto de patrimonio como objeto de construcción histórica y sus efectos en el contexto de las prácticas sociales actuales. Observar la relación entre Cultura, Identidad Nacional y Patrimonio. Discutir el concepto de Patrimonio Disonante a través de un estudio de caso, el Monumento a Fernando I Gran Duque de Toscana, conocido como Los Cuatro Moros. Metodología: Se trata de un estudio cualitativo de carácter teórico, por lo tanto bibliográfico, que pretende, de forma ensayística, lanzarse de la mano de cuestiones epistemológicas. Resultados: La propuesta de utilizar el concepto de patrimonio disonante juega un papel de crítica a la violencia de la modernidad, y puede centrarse en la elaboración de una memoria cultural que se enfrente a las diferentes jerarquías étnicas, de clase y de género. Consideraciones finales: La elaboración y aplicación del concepto de patrimonio disonante permite que el patrimonio cumpla la función: de reorganizar las memorias de manera integral y ya no atada a la idea de unificar las culturas de las identidades nacionales.

Descriptores: Patrimonio disonante; Monumentos; Políticas de patrimonio; Epistemología; Democratización de la cultura.

Recebido em: 31.08.2021

Aceito em: 01.09.2021 